\title{
Overconfidence and Investment: An Experimental Approach
}

A positive relation between overconfidence and investment provision has been theoretically justified and practically assumed in the literature, but has not been thoroughly investigated. We test and confirm this positive relation between direct measures of overconfidence in one's financial knowledge and choice of investment. More precisely, strong overconfidence results in excess investment, underconfidence induces underinvestment, whereas moderate overconfidence leads to accurate investments. Our experimental results are based on different subject pools, financial professionals and students, and different media: computer-, paper-, and web-based. The degree of one's overestimation of one's individual financial knowledge relative to one's actual knowledge as well as relative to the knowledge of peers explains investment decisions better than one's actual knowledge. The relation between overconfidence and investment is robust to the degree of individual risk aversion, the riskiness of the investment projects, and to the changes in incentives structure.

JEL Classification G11, J22

Keywords: Overconfidence, Better-That-Average, Bias, Investment, Risk Aversion, Professionals

(C) 2017. This manuscript version is made available under the Elsevier user license 
Self-confidence or believing in one's own abilities is widely believed to be a prerequisite for success. Moreover, self-confidence keeps a person happier and more satisfied with her life; it may help persuade potential employees, business partners, or life companions that this person possesses positive characteristics and high abilities. It boosts motivation to undertake new projects or continue old ones in the face of obstacles, failures, or lack of willpower. However, one can also be too self-confident and many negative effects of overconfidence have been proposed in the literature. ${ }^{1}$ It is conceivable that the beneficial effects of self-confidence can be traded off against the detrimental ones, such that there is an optimal level of confidence in a specific context.

In this study, we investigate the potentially beneficial effects of moderate overconfidence on investment provision. Our experimental design enables us not only to measure individuals' overconfidence in a specific domain directly, but also to assess ability and confidence in ability in the same domain, namely, financial decision making. We define overconfidence as the difference between a person's belief about her competence in the financial domain and her actual competence.We measure overconfidence in two different ways: overestimation (or optimism) when subjects assess their ability, achievements, level of control, or probability of success to be higher than they actually are (Moore and Healy (2008)) and better-than-average (or overplacement) when subjects believe that they are better than others. ${ }^{2}$ Both overestimation and overplacement refer to an inclination to overestimate performance (e.g. the number of correct answers a person gives in a quiz or future market index returns) either in comparison with the actual performance or in comparison with the performance of others. After we measure the participants' ability and overconfidence in the financial decision-making domain, they make investment choices in a set of different investment projects, where their personal income depends on their financial knowledge and investment level as well as risk. We run our experiment with students who pursue majors in business and economics as well as with financial professionals (comprising financial managers, financial consultants, and bankers) who have a degree in financial economics as well as experience in the financial domain.

We find that our participants' confidence in their financial knowledge is higher than their actual knowledge and that most participants also believe that they are better than average. While professional managers actually have higher financial knowledge/skill than students in business and economics, a majority of these financial managers is still overconfident. We find that overconfidence and underconfidence are associated with investment choices that are not value-maximizing: the participants in the highest

1. See for example, studies by Barber and Odean (2001); Fenton-O'Creevy et al. (2003); Malmendier and Tate (2005); Malmendier and Tate (2008); Schrand and Zechman (2012); Deshmukh, Goel and Howe (2013); Hribar and Yang (2015); Aktas et al. (2016)

2. We do not consider overprecision when subjects express excess certainty in their beliefs and give too narrow intervals for possible realizations of future events. In general, overprecision refers to a tendency to underestimate the variability of phenomena (e.g., volatility of future market returns). 
overconfidence quartile choose inappropriately high investment levels and, likewise, the underconfident individuals choose inappropriately low investments. In our experiment, only moderately overconfident subjects are well calibrated in that they tend to choose accurate investment levels.

These findings are valid for overconfidence as defined in relation to one's own ability and as defined in relation to the ability of others (better-than-average), with the former type of overconfidence being more detrimental in that it leads to worse investment decisions. Our findings hold also when we (i) manipulate the incentive scheme for the participants such that incorrect investment choices lead to strong pecuniary penalization, (ii) control for participants' risk aversion, and (iii) vary the degree of uncertainty that an investment choice yields specific revenues. The results are valid both for students as well as financial professionals. The results do not depend on whether the data are collected in the lab or in a webbased manner, nor do they depend on whether the investment choices are made on paper or based on computerized information.

We contribute to the overconfidence literature in the following ways. First, following Malmendier and Tate (2005), many studies in the finance literature use personal managerial investments, specifically stock-option holdings, as a proxy for managerial confidence. This proxy is likely to reflect a mixture of different manifestations of overconfidence, such as overestimation, overprecision as well as illusion of control. However, a relation between different overconfidence measures and chosen investment has not been thoroughly investigated and corroborated in the empirical literature. In our experiment, we use overestimation and overplacement (better-than-average) measures of overconfidence and we are able to evaluate their roles in investment provision separately: we find that overestimation is a stronger predictor of investment provision than better-than-average.

The lack of empirical corroboration in the literature of a relation between overconfidence and investment can be explained by practical difficulties in distinguishing between confidence and actual ability. Without a proper reference point (a person's actual ability), it is impossible to identify whether that person overestimates or underestimates her skill in a specific domain. For example, Ben-David, Graham and Harvey (2013) use forecasts of S\&P500 made by financial professionals and compare those forecasts with historical and realized S\&P500 performance to obtain measures for professionals' optimism and miscalibration. Still, those forecasts are unrelated to individuals' beliefs about their own ability but rather reflect their expectations about future economic growth. Thus, our second contribution consists of the fact that our experimental design enables us to measure an individual's skill separately from her beliefs about her skill, which allows us to pinpoint moderate and strong overconfidence as well as underconfidence.

Third, we show that our results hold for different types of subjects: financial laymen with a bonafide affinity for finance as indicated by the fact that they are students enrolled in business or economics 
university programs, and financial professionals proper, such as financial managers, bankers, and financial consultants. Our results are in accordance with the literature showing that professionals and students make decisions along similar lines (Glaser, Langer and Weber (2007, 2013); Menkhoff, Schmeling and Schmidt (2013)). Fréchette (2011) gives an overview of the differences in the behavior of students and professionals who are defined as people working in a field closely related to the economic "game" in question. Remarkably, only in 1 study out of 13 under consideration, the behavior of professionals is closer to the theoretical predictions than that of students. In all other cases, the professionals suffer from behavioral biases to the same extent or even more than laymen do.

Finally, we test whether our results differ across media, by performing the experiment on a computer in a lab, on paper in a classroom, and by means of a web-based tool. While lab studies have become the standard, the appropriateness of web-based experiments is still subject to an intense debate. ${ }^{3}$ We contribute to the above debate by demonstrating that the positive effects of overconfidence on investment arise irrespective of whether they are assessed in lab-, paper- or web-based situations.

The remainder of the paper proceeds as follows. The next section describes a model which motivates the research question and introduces the empirical predictions. Section II details the experimental design. The results are provided in Section III and discussed in Section IV, which also describes some caveats of the study. Section V concludes.

\section{Motivating Model and Empirical Predictions}

To motivate our empirical predictions, we develop a simple model that provides the intuition on why overconfidence may lead to higher investment. Our model is a special case of the one by Campbell et al. (2011). We consider a one-period profit maximization problem whereby a manager decides how much to invest in a specific project, where the revenue function has decreasing returns to scale.

The manager chooses an optimal investment level $i^{*}$ in a project, where the project revenue is defined by the manager's revenue function $R(i, s)$. The revenue function depends on investment level $i$ and managerial skill level $s$, with the following properties $R(0, s)=0, R_{i}>0, p_{i i}<0, R_{s}>0, R_{s i}>0$, and $\lim _{i \rightarrow 0}\left(R_{i}(i, s)\right)=+\infty$, which guarantee that a strictly positive investment level is always optimal for any skill level $s>0$. The manager does not know her ability $s$, so her optimal investment choice is determined by her beliefs about her personal skill. To model potential biases in a manager's beliefs, we assume that she perceives her skill level as $\tilde{s}$, where $\tilde{s}=s$ corresponds to unbiased beliefs, $\tilde{s}>s$

3. The results of internet-based experiments are mostly found to be similar to those from lab experiments (see also Anderhub, Müller and Schmidt (2001); Gosling et al. (2004); Chesney et al. (2009); Duersch, Oechssler and Schipper (2009); Horton, Rand and Zeckhauser (2011); Amir and Rand (2012)) 
corresponds to overconfidence and $\tilde{s}<s$ to underconfidence.

For simplification, we assume that the manager is risk neutral and her compensation is proportional to the project profit. ${ }^{4}$ The manager's problem is to maximize the project profit given her beliefs about her skill level $\tilde{s}$, where the project profit equals the difference between the project revenue and the chosen investment level. Thus, the manager's problem can be written as follows:

$$
\max _{i} R(i, \tilde{s})-i
$$

with the first order condition of

$$
R_{i}\left(i^{*}, \tilde{s}\right)=1
$$

Thus, belief $\tilde{s}$ determines a manager's investment choice: a manager with a higher belief $\tilde{s}_{h}$ chooses a higher investment level than her peer with a lower belief $\tilde{s}_{l}$, irrespective of the actual skill levels of both managers.

LEMma 1. Consider two managers with the same investment functions, but different beliefs about their skill levels $\tilde{s}_{h}$ and $\tilde{s}_{l}$, where $\tilde{s}_{h}>\tilde{s}_{l}$. Then, the manager with a higher belief $\tilde{s}_{h}$ chooses a higher investment level, $i_{h}^{*}>i_{l}^{*}$.

Using $i^{*}(\tilde{s})$ as an implicit function, equation (2) can be rewritten as follows: $R_{i}\left(i^{*}(\tilde{s}), \tilde{s}\right)=1$. We differentiate the previous equation with respect to $\tilde{s}$ to calculate whether $i^{*}(\tilde{s})$ increases or decreases in $\tilde{s}: R_{i i}\left(i^{*}(\tilde{s}), \tilde{s}\right) \cdot i_{\tilde{s}}^{*}+R_{i \tilde{s}}\left(i^{*}(\tilde{s}), \tilde{s}\right)=0$. Then $i_{\tilde{s}}^{*}=-R_{i \tilde{s}} / R_{i i}>0$ because $R_{i s}>0$ and $R_{i i}<0$. Thus, the investment level chosen by a manager increases in her belief $\tilde{s}$ about her skill level: a manager with a higher belief $\tilde{s}_{h}$ about her skill level would choose a higher investment level $i_{h}^{*}>i_{l}^{*}$ than her peer with a lower skill estimation, $\tilde{s}_{l}$.

Lemma 1 implies that if a manager's belief does not accurately reflect her actual skill level, $\tilde{s} \neq s$, then her investment choice does not maximize the project profit. More specfically, overconfident managers $\tilde{s}_{o c}>s$ overinvest and bear unnecessary costs that decrease their final compensation, whereas underconfident managers $\tilde{s}_{u c}<s$ choose investment levels lower than optimal and suffer from underproduction. Figure I illustrates both situations.

Our model predicts that the investment level increases in a manager's confidence about her skill and this effect is symmetric for both under- and overconfident managers. Moreover, overconfident managers

4. If the manager is risk-averse, the model's predictions do not change as the manager's problem does not involve any risky decisions. However, two extensions are possible. Revenue can be a noisy function of manager's investment or the manager can hold probabilistic beliefs about her skill level. In both cases, a risk-averse manager underinvests, and moderate overconfidence brings her investment choice closer to the optimal level. 
overinvest and underconfident managers underinvest in comparison to the optimal investment level given their actual skill. In other words, our model yields the following predictions.

Prediction 1: For a given skill level, the higher the manager's overconfidence the higher her investment choice.

Prediction 2: The above effect holds for both under- and overconfidence, i.e. underconfidence results in underinvestment and overconfidence leads to excessive investment.

\section{EXPERIMENTAL DESign}

The participants of our experiment act as managers who make investment decisions. Each experiment consists of two parts. In Part 1, we assess the subjects' skill and (over)confidence in the finance domain, whereas in Part 2, subjects make investment decisions in a series of projects, where their reward depends on their investment level and their skill level achieved in Part 1, and is maximized when they make investment decisions that are congruent with their actual skill level. Subjects are not told about their performance in Part 1 so their decisions in Part 2 are based on their beliefs about their skill level. We use their (over)confidence in their financial knowledge in Part 1 as a proxy for their beliefs about their skill level and compare it with their actual or average skill level to obtain overestimation and better-thanaverage measures. Finally, we relate these measures to investment level choice in Part 2.

\section{II.A. Measures of Skill and Overconfidence (Part 1)}

The subjects answer 20 financial knowledge questions (see Appendix A) to measure their skill level, which corresponds to the level of their financial knowledge. ${ }^{5}$ For each question, the subjects are asked to choose the correct answer from two alternatives. After making their choice for each question, they assign a probability that the choice is correct (between $50 \%$ and $100 \%$; both extremes are also allowed). A subject's average probability that she has correctly answered the questions corresponds to her subjective confidence in her financial knowledge. We expect that subjects with higher confidence levels will choose higher investment levels in Part 2.

[Insert Table I about here]

5. Among others, our questions include those proposed by Van Rooij, Lusardi and Alessie (2011). We also include three questions from the cognitive reflection task by Frederick (2005). 


\section{II.B. Investment (Part 2)}

At the beginning of Part 2, subjects decide on their personal skill level according to Table I. ${ }^{6}$ Their skill level is constant during Part 2 and is defined only by the number of correct answers they gave in Part 1. Subjects are not told about their performance in Part 1, so they have to form a belief about the number of correct answers they gave and the resulting skill level.

In our experimental task, subjects choose an investment level to maximize their earnings in different projects (see below). In each project, subjects' earnings are equal to the realized revenues plus an initial endowment of 500 cent minus the cost of investment. ${ }^{7}$ The cost of investment depends only on the chosen investment level and grows from 60 cent for investment level 1 up to 500 cent for investment level 5 (see the last column of Table II, all Panels).

\section{Basic Project}

In the Basic Project, ${ }^{8}$ five different investment levels are available and the revenue function is a discrete approximation of the investment function discussed in the Section I. Panel A of Table II presents five different investment levels available in the Basic Project, along with their monetary costs and revenues depending on a subject's skill level.

Without loss of generality and to guarantee a unique optimal investment level for each skill level, the revenue function is constructed in a way that earnings (revenues plus endowment minus cost of investment) are the highest only when the chosen investment level equals a subject's actual skill level. Both under- and overestimation of skill lead to suboptimal investment choices. So, in order to maximize their earnings, subjects with skill level 1 should choose investment level 1 , subjects with skill level 2 should choose investment level 2, etc.

[Insert Table II about here]

\section{Strong Incentives Project}

Whereas the Basic Project has a realistic revenue function, it may fail to provide subjects with sufficiently strong incentives to form unbiased beliefs about their personal skill level. Consider a subject with skill level 3. If she estimates her skill level correctly, she chooses investment level 3 and receives 1130 cent. $^{9}$

6. The number of correct answers required for a certain skill level was defined in a pre-experimental pilot study and in such a way that the proportion of subjects in each skill group is approximately the same. None of the subjects from the pilot study participated in the subsequent main experiment.

7.1 Euro was about 1.32 USD at the time of the experiment.

8. In the experiment, projects are referred to using ordinal numbers to avoid any framing effects.

9. Earnings equal revenues plus endowment minus cost of investment. When skill level is 3 and chosen investment level is 3 , earnings are $850+500-220=1130$ cent. 
If she believes that her skill level is 4 and wrongly chooses investment level 4 , she receives 1060 cent in earnings. Thus, by being overconfident and by choosing excessively high investment level, the subject loses only 70 cent. If, in addition, she extracts some positive utility from thinking that her ability (in this case, financial knowledge) is higher than it is in reality, then it is conceivable that the incentives in the Basic Project are not strong enough to ensure unbiased skill assessment.

To provide subjects with stronger incentives, we introduce another project, which is called the Strong Incentives Project (see Table II, Panel B). In this project, subjects' revenues are positive only when they correctly choose an investment level equal to their actual skill level, and zero otherwise. In other words, it is not possible to achieve higher revenues by choosing a higher investment level as it was in the Basic Project. So, in the Strong Incentives Project, it is not possible to substitute skill with investment. The subjects still bear the costs of the chosen investment, which are independent of the realized revenues and are the same as in the Basic Project.

\section{Loss Aversion Control Project}

If subjects are loss averse and set a reference point at their initial endowment of 500 cent then, while making their investment choice in the Strong Incentives Project, they may become more conservative in their skill level estimation and may even become underconfident. Consider the following example. A subject believes that her skill level equals 4 with probability $p>0.5$ and 3 with probability $1-p$. If she chooses investment level 4 , then with probability $1-p$ she incurs a loss of 340 cent and if she chooses investment level 3 , then with probability $p$ she loses only 220 cent. If the subject is loss averse, then she may choose investment level 3 even if she assigns a higher probability to skill level 4 . To insure that subjects' choices are not affected by their loss aversion, we introduce the Loss Aversion Control Project (see Table II, Panel C).

The Loss Aversion Control Project provides subjects with identical incentives to estimate their skill level correctly irrespective of their actual or believed skill level and of their loss aversion. In this project, the costs of every investment level are the same and equal 220 cent. Thus, if a subject chooses the investment level corresponding to her actual skill level, then she receives 1130 cent in earnings; otherwise she receives zero. Note also that in this project both overconfidence and underconfidence are equally costly.

\section{Risky Project}

In reality, the investment output is often affected by random shocks that do not depend on a manager's skill or investment and cannot be predicted. To explore whether risk changes subjects' choice of invest- 
ment level, we set up the Risky Project, in which revenues are subject to random shocks (see Table II, Panel D). The shock takes values of $-50,-40,-30,-20,-10,0,10,20,30$, 40, or 50 cents with equal probability. The expected revenues value for every investment-skill combination in the Risky Project is equal to the revenues value for the corresponding investment-skill combination in the Basic Project (Table II, Panel A).

\section{II.C. Final Payment}

Before subjects receive any feedback about their performance, we collect their risk preferences, social characteristics, as well as their beliefs about their own skill level and those of their peers. Then, subjects can see their realized earnings in each project and one project is randomly drawn to determine their final earnings. Finally, subjects write down their final earnings and their bank account number on a receipt, privately hand in their receipts to an experimenter, and leave the lab.

\section{RESULTS}

To assess the generalizability of the effects of overconfidence on investment provision, the experiment was conducted with three different media and repeated with two different subject samples. The first subject sample consisted of 111 graduate and undergraduate students with majors predominantly in Business or Economics. They took part in a Z-tree-based experiment (Fischbacher (2007)) at the CentERLab of Tilburg University, the Netherlands. The second subject sample consisted of 147 financial professionals. Of these, 33 financial professionals participated in a paper version of the experiment at the Tias School for Business and Society, Tilburg University; and 114 financial professionals completed an online Qualtrics version (Qualtrics Labs Inc., Provo, UT) of the experiment. ${ }^{10}$ Whereas students were provided with real monetary incentives (the average final earnings were 12.84 Euro), the professionals in both cases made hypothetical choices. Henceforth, we label BSc/MSc students and financial professionals as 'students' and 'professionals', respectively. Depending on the sample and medium, we also refer to 'lab-based student sample', 'paper-based professional sample', and 'web-based professional sample'.

10. Financial professionals in our sample are financial managers, bankers, financial consultants, etc., who followed an executive education at Tias School of Business and Society (and are alumni of the Executive Master in Finance or Executive Master in Business Valuation). For the online version, we personally contacted (via a phone call or an e-mail) 214 professionals; from those, 156 started the survey and 114 finished it. To insure single-time individual participation, each participant received a personalized link to login into the Qualtrics software, valid for 6 weeks. 


\section{III.A. Subject Characteristics}

Our subject samples are characterized by the following features (see Table III). First, the student sample is more heterogeneous in terms of gender and nationality than the professional sample. While there are $40.5 \%$ women among the students, there are only $11.6 \%$ women in the professional sample. There is also more variation in the nationalities among students (European and Asian subjects), ${ }^{11}$ whereas the professional pool is dominated by Europeans, mostly Dutch. Then, our samples are relatively homogeneous in terms of major as both students (with current degrees in Economics and Business) and professionals have (had) financial economics in their university training. Moreover, a finance affinity is present in virtually all professionals' CVs: banking, financial consulting, and financial management are their occupations in almost equal parts. Finally, as would be expected, work experience varies across the subject samples. The students have little or no experience in the financial industry, whereas the professionals report extensive working experience: 104 out of 147 professionals (71\%) have gained work experience of 12 years or more. Thus, our combined subject sample comprises participants with different personal characteristics and professional experience, who have a strong affinity to finance and economics through education and/or their professional activities.

\section{III.B. Financial Knowledge and Overconfidence}

To quantify actual skill, we use performance in the financial knowledge questionnaire. On average, students give 14.11 correct answers, which is 1.37 and 3.00 fewer correct answers than professionals give in the paper- and web-based samples respectively (see column (1) of Table IV). The higher professionals' performance reasonably results in higher average confidence in their financial knowledge (see column (2)). In the web-based professional sample, the subjects believe that on average $89.03 \%$ of their answers are correct, while the students estimate that $86.03 \%$ of their answers are correct. Moreover, the professionals in the paper-based sample express the same level of confidence in their financial knowledge as their peers in the web-based sample, in spite of giving fewer correct answers; the Confidence between the two professional samples is not statistically different $(t=1.39, p=0.17)$

The difference in performance between the student and professional samples is likely to be due to the professionals' superior knowledge and practical experience in finance. Although they have little bearing on the primary focus of the paper (relation between overconfidence and investment choice), other points that may be worthy of consideration are the following. The positive difference in the questionnaire performance between the paper- and web-based professional samples could result from more relaxed level.

11. All the experiments were conducted in English and all participants had had finance courses in English at university 
time constraints for the latter sample and from a difference in education (as the latter had completed the executive finance programs whereas the former were only half-way). The subjects participating in the laband paper-based experiments were given only a limited amount of time to answer 20 financial knowledge questions and to indicate their confidence levels. On the contrary, the subjects of the web-based version could spend as much time as they wanted. ${ }^{12}$ The professionals in the web-based sample took longer to fill in the questionnaire than the students in the lab experiment (see column (3) of Table IV). However, the time spent to fill in the questionnaire did not increase their performance. The correlation between response time and number of correct answers is not different from zero in both samples: for the students the correlation coefficient is $-0.01(p=0.93)$ and for the professionals (web-based) it is $-0.04(p=0.67)$.

To investigate whether subjective confidence levels accurately reflect their performance, we follow the psychology literature and calculate a calibration-based overconfidence measure, CBO. CBO is the difference between a subject's average confidence in her answers (Confidence) and the actual number of correct answers she gave, divided by 20 (the total number of questions). Positive values of CBO indicate that the subjects' confidence in their financial knowledge is higher than their actual performance and that they believed that they gave more correct answers than they actually did, i.e. they are overconfident. Negative CBO values imply that the subjects underestimate their financial knowledge. ${ }^{13}$

As expected, on average subjects are significantly overconfident, see column 4 of Table IV. The students overestimate their financial knowledge by $15.49 \%$, the professionals by $13.67 \%$ and by $3.46 \%$ in the paper- and web-based experiment versions, respectively. In the lab environment (computerized or paper-based), both the students and professionals demonstrate similarly high levels of overconfidence (diff. $=1.82, t=1.15, p>0.10$ ). Although in the web-based version professionals appear to be better calibrated due to better performance, their average CBO of $3.46 \%$ is still significantly above zero $(t=3.91$, $p<0.001)$. Here again, the time spent to answer the questions is not significantly correlated with CBO.

We also analyze whether subjects consider their financial knowledge to be above the financial knowledge of an average participant in their peer group. In the final questionnaire, subjects report their beliefs about the number of correct answers they and their peers gave in the financial knowledge questionnaire. ${ }^{14}$ We set a dummy variable BtA (better-than-average) equal 1 for those subjects who believe to give more

12. For the computerized (lab- and web-based) versions, individual response time is recorded. In the paper-based version, time was constant across subjects as they all received and handed in their questionnaires simultaneously, which obviously does not exclude some unobservable variation in response time.

13. We also repeat all our analyses using an alternative measure of overconfidence, which is the difference between the number of correct answers the subject believes she gave and the actual number of correct answers she gave. The results essentially are the same. We use CBO in the paper because it is the measure most-often used in the literature.

14. The exact questions are as follows. i) You were asked to answer 20 financial knowledge questions. For how many of these questions do you think you gave the correct answer? (State a number between 0 and 20.) ii) Other participants were asked the same 20 financial knowledge questions. For an average participant in this experiment how many answers do you think were correct? (State a number between 0 and 20). 
correct answers than their peers, and 0 otherwise; see Table IV, column (5). Despite the fact that on average subjects are well calibrated (exactly half of them believe to have above-average financial knowledge), only 63 percent estimate their performance correctly relative to the others.

Panel C of Table IV explores the effect of subject characteristics on their performance in the financial knowledge questionnaire, their confidence in their financial knowledge, the amount of time they spent to answer the questions, as well as on their overconfidence, both in terms of the CBO and BtA measures. We perform this comparison for the student sample only, as we do not find enough variation in gender, cultural and educational background among the professionals (see Table III).

In line with the previous literature, we find that men display significantly higher financial literacy and also express higher confidence in their knowledge than women do (see Lusardi and Mitchell (2014) for a detailed review). In our case, female students demonstrate slightly higher levels of overconfidence than male students as measured by the CBO measure: the difference between the two groups is significant at the $10 \%$ level. Nevertheless, men are much more likely to perceive their performance to be above average, whereas women tend to underestimate their financial knowledge when compared to others.

We also document that Dutch (local) students spend significantly less time to answer the financial knowledge questions than their international peers (who are not native English speakers). Though all the students participating in our experiment had a good command of English, Dutch students probably had superior knowledge of the language in comparison with international students, which allowed them to go through the questionnaire faster. Nevertheless, the differences in the amount of time spent to answer the questions do not result in differences in performance or (over)confidence. Finally, we find that a major in Business gives students a significant advantage in answering our financial knowledge questionnaire: on average, they give 1.71 correct answers more than their peers studying other majors, including those in Economics; the difference is significant at the $1 \%$ significance level $(t=2.85)$.

\section{III.C. Skill and Investment Choice}

Before analyzing the relationship between overconfidence and investment, we compare subjective investment choice across different projects (see Table V, Panel A). In the experimental design (see section II.B.), we indicate that in the presence of overconfident subjects, the incentives in the Basic Project may be too weak to ensure unbiased skill assessment. To account for this potential issue, we introduce the Strong Incentives Project. In the computer-based student sample, the subjects on average choose higher investment levels in the Basic Project than in the Strong Incentives Project (diff. $=0.15, t=2.02$, $p<0.05)$, which is in accordance with our conjecture. 
We also hypothesize that in the Strong Incentives Project subjects may become relatively more conservative in their skill estimation due to their loss aversion (see section II.B.). Indeed, in the student sample, the subjects choose lower investment levels in the Strong Incentives Project than in the Loss Aversion Control Project (diff. $=-0.13, t=1.85, p<0.10$ ). However, we cannot confirm the same pattern for the professional samples. In the paper-based professional sample, all 33 subjects chose exactly the same investment levels in the Strong Incentives and in the Loss Aversion Control Projects. By contrast, in the web-based professional sample, the difference between the subjects' investment choice in the Strong Incentives and in the Loss Aversion Control Project is positive and significant (diff. $=0.44, t=3.19$, $p<0.001)$. Finally, we find no significant difference in the subjective investment level choice between the Basic and Risky Projects (diff. $=-0.05, t=0.65, p>0.10$ ) for the student sample. Taken together, these results suggest that the differences in subjective investment choices across different projects are moderate.

We also compare the subjective average investment level choice with the subjects' actual skill level (see Table V, Panel B). As expected, the professionals have significantly higher skill level than the students do. For example, the students on average achieve a skill level of 2.88 , whereas the professionals in the web-based experiment version attain a skill level of 3.82 (diff. $=-0.94, t=5.85, p<0.001$ ). In the previous section, we found that while all subjects overestimate their financial knowledge according to our CBO measure, the students do so to a greater extent than the professionals do. This difference in overconfidence translates into excessive investment levels for the student samples and accurate investment choice for the professional samples. In the student sample, the subjects choose investment levels, which are 0.56 higher than the subjects' actual skill levels $(t=4.08$, both $p<0.001)$. On the contrary, in the paperand web-based professional samples, the subjects on average choose investment levels corresponding to their actual skill levels. Note, that an adequate average investment choice exhibited by the subjects in the professional sample does not exclude a situation where overconfident subjects overinvest and underconfident subjects choose insufficient investment levels. In the next section, we directly test the relationship between overconfidence and investment choice.

We further investigate whether subjects with better financial knowledge are more likely to correctly choose the optimal investment level in different projects of our experiment. We define a dummy variable Optimal Choice that is equal to 1 if a subject makes an optimal investment choice in a given project, that is, if she chooses an investment level corresponding to her actual skill level; and 0 otherwise. For each subject sample and for each project separately, we estimate a probit model for the Optimal Choice variable, where the main explanatory variable is Skill. ${ }^{15}$ We also control for the subjects' personal 
characteristics: gender, age, education, nationality, work experience, and occupation (the last two only apply to the professionals). The results are reported in Table VI. In the majority of the projects, the coefficient for Skill is positive and significant. Thus, in line with the previous literature, ${ }^{16}$ we find that subjects with higher financial literacy are better in choosing optimal investment levels.

\section{III.D. Overconfidence and Investment}

To test prediction 1, we partition the subjects of each sample into four CBO-based quartiles with subjective overconfidence increasing by quartile. As the subjects' investment choices do not significantly vary from one project to another, we calculate the Investment variable for every subject as the difference between her average investment choice across the projects and her Skill. For the student sample, we take the average investment level chosen by the subjects in the four projects (Basic, Strong Incentives, Loss Aversion Control, and Risky) and for both professional samples, we use the average investment level choice in the two projects (Strong Incentives and Loss Aversion Control). We compare the difference in the subjects' Investment across four CBO-quartiles (see Figure II).

In the student sample, the subjects' investment significantly varies across CBO quartiles (see Figure II.a). Despite the fact that the students in the bottom CBO quartile appear to be unbiased (CBO equal to $-0.15 \%, t=0.17, p>0.10$ ), they systematically underinvest: Investment is significantly negative $(t=3.60, p<0.001)$. The subjects in the $2^{\text {nd }} \mathrm{CBO}$ quartile, with a moderately positive but significant CBO of $9.56 \%(t=17.80, p<0.001)$, select accurate investment levels: Investment is zero. The highly overconfident subjects in the $3^{\text {rd }}$ and top CBO quartiles choose excessively high investment levels: Investment equals 1.00 and 1.78 respectively $(t=4.20$ and $t=9.12$ respectively, both $p$-values are less than 0.001).

Figures II.b and II.c present Investment across CBO quartiles for the paper- and web-based professional samples. In line with our previous findings, the subjects in the bottom CBO quartile substantially underinvest: Investment is -0.89 and -0.81 respectively $(t=2.29 ; t=4.61$, both $p$-values are less than 0.10). In the $2^{\text {nd }}$ and $3^{\text {rd }} \mathrm{CBO}$ quartiles, the subjects are on average slightly overconfident and are well calibrated in their choice of investment levels: Investment is not statistically different from zero. In the top CBO quartile, professionals are significantly overconfident and choose inappropriately high investment levels in both paper- and web-based samples.

Thus, our univariate analyses demonstrate that subjective overconfidence increases investment (pre-

knowledge questionnaire, 2 if she gives 12 or 13 correct answers, 3 if 14 or 15,4 if 16 or 17 , and 5 if the subject answers 18 , 19 , or 20 questions correctly.

16. See, for example, Aier et al. (2005); Campbell (2006); Lusardi and Mitchell (2011); Calvet, Campbell and Sodini (2009); Lusardi and Tufano (2009); Van Rooij, Lusardi and Alessie (2011); Almenberg and Dreber (2015); 
diction 1), whereas underconfidence and strong overconfidence result in under- and overinvestment (prediction 2). Moreover, in our experiment, moderately overconfident subjects (with a CBO of about 5-15\% for the student sample and about 3-10\% for the professional sample) tend to choose accurate investment levels, whereas those with higher/lower overconfidence tend to choose inappropriately high/low investment levels. Our results also suggest that professional experience and better financial knowledge do not affect the positive relation between overconfidence and chosen investment level.

One may argue that the above positive relation between confidence and chosen investment is mechanical and mostly driven by subjects' skill. For example, more skilled subjects can be rightfully more confident and therefore choose higher investment levels. Moreover, according to our CBO measure, highskilled subjects have less scope to be overconfident: given a fixed confidence level, a subject's CBO decreases with the number of correct answers given by the subject. To address this issue, we conduct a multivariate analysis, where we control for the subjects' actual skill and personal characteristics.

\section{III.E. Regression Analysis}

Our main dependent variable is Average Investment (the mean of the investment levels chosen by a subject in different investment projects); but we also repeat the analysis using subjects' investment choice in each individual project. Our explanatory variables include CBO, Skill, and subjects' personal characteristics: gender, age, education, nationality, work experience, and occupation (the last two only apply to the professionals). ${ }^{1718}$ The results are reported in Table VII.

In line with prediction 1 , we find that the coefficient for $\mathrm{CBO}$ is positive and significant in all subject samples and in all specifications, including those for individual projects. We confirm the results found in the previous section: the higher the subjects' overconfidence in their financial knowledge, the higher their chosen investment levels (Table VII, Panels A-C). Moreover, we observe no significant difference in the above relation for the paper-based and web-based professional samples (Table VII, Panels $\mathrm{B}^{19}$ and C). In other words, it does not matter whether the professionals performed the task in class with paper and pencil or at home in front of their computers.

Note that the coefficient for Skill is significantly smaller than 1 in all specifications in the student sample and for the Average Investment and the Strong Investment Project for the web-based professional

17. We also measure subjects' risk aversion via the Holt and Laury (2002) task and cognitive reflection score (CRS) via the questions by Frederick (2005). Our main results do not change, when we restrict the sample to high-CRS subjects only or to those who make consistent choices in the Holt and Laury task (tables available upon request).

18. As a further robustness test, we exclude from the analysis those subjects who are either in the top or bottom $5 \%$ in terms on the average decision time. Those who spend too little time may not have taken the task seriously enough and those who spend too much time are either confused or distracted. Our results stay unchanged (tables available upon request).

19. In this panel, all three columns report the same numbers as all 33 subjects gave exactly the same answers. 
sample. If subjects were able to predict their performance in the financial knowledge questionnaire perfectly, then a value of 1 would be expected for the Skill variable and a value of 0 for the CBO variable. Taken together, these results suggest that subjects' investment choice strongly correlates with their overconfidence but not so much with their actual skill level.

To further test prediction 2, we investigate how different forms of overconfidence affect subjects' propensity to select investment levels. As there may be a multicollinearity issue between CBO and Skill (their VIFs in model (1) of Table VII are above 2.5), we make CBO and Skill orthogonal by regressing CBO on Skill and taking the residual. First, we re-estimate model (1) of Table VII using this new CBO measure. The results are presented in model (1) of Table VIII. Our main result does not change: calibration-based overconfidence has a positive effect on investment choice as the coefficients for CBO are positive and significant for all subject samples. This transformation does not affect the coefficient of $\mathrm{CBO}$, but increases the coefficient for Skill in absolute value.

To test the implication of prediction 2 that under- and overconfidence affect investment choice symmetrically, we split the $\mathrm{CBO}$ measure in two: above and below the CBO median for each sample (see model (2)). If the relationship between underconfidence and underinvestment is different from the one between overconfidence and overinvestment, we should find different coefficients for the Low CBO and High CBO variables. For the student sample, we find that the coefficient for Low CBO is positive and significant, whereas the coefficient for High CBO is positive but insignificant. For the paper-based professional sample, the pattern is reversed: the coefficient for Low CBO is insignificant and the coefficient for High CBO is significant. For the web-based sample, both coefficients are significant at the $5 \%$ level. However, for all three samples we cannot reject the null hypothesis that the coefficients are the same: the F-statistics are $F_{103}=1.26, F_{21}=0.14$, and $F_{102}=0.65$ respectively. Thus, we obtain no consistent evidence that under- and overconfidence differently affect investment decision-making, which is what prediction 2 implies.

To test whether overestimating one's abilities relative to others affects one's investment decisions, we regress Investment on a dummy variable BtA (better-than-average; see model (3)). The coefficient of BtA is positive and significant for all subject samples. In model (4) we put both overconfidence measures, $\mathrm{CBO}$ and $\mathrm{BtA}$, into the regression. The estimates for the $\mathrm{CBO}$ coefficient are relatively unaffected in comparison with model (1), but the coefficient of BtA stays significant only in the student samples (see Panel A). Thus, not only subjects' ability overestimation relative to their actual ability but also relative to the ability of others can positively affect subjects' propensity to overinvest. However, overestimation of one's own abilities appears to have a more robust effect than than the view that one is better than average. 
Finally, in model (5) we exclude all measures of overconfidence and use only Skill as the main explanatory variable. Note that model (5) delivers the lowest R-squared in comparison with models (1) through (4) for all subject samples. This result suggests that subject's investment decision-making is strongly affected by their beliefs and biases in those beliefs. Thus, it is important to measure beliefs and self-assessments correctly and to take them into account when explaining investment behavior in our task.

\section{Effect of Subjects' Risk Attitude}

Finally, we investigate how investment in our projects is affected by subjects' risk attitudes and whether this relationship is affected by their overconfidence. In general, more risk averse individuals should be less willing to invest in risky gambles. In our experiment, the primary source of risk is a subject's own skill level, because she does not know it for sure and only holds a (potentially biased and probabilistic) belief about it. Moreover, in the Risky Project revenues are subject to an additional source of risk, random shocks ranging between -50 and 50 Cents (see Table II, Panel D). Overall, subjects with higher levels of risk aversion are likely to choose lower investment levels in all of the projects than their less risk-averse peers. This effect is likely to be the strongest in the Risky Project.

We measure subjects' risk aversion as the number of safe choices they make in a standard Holt and Laury (2002) task. In this task, subjects make 10 choices between two options: Option A and Option B. Option A is safe and Option B is risky but delivers a higher expected payoff starting from the decision number 5 onwards. Risk-neutral subjects should make exactly 4 safe choices and switch from Option A to Option B at decision number 5, whereas risk-averse subjects should switch later and make more safe choices. The more risk averse the subjects are, the later they should switch to the riskier Option B. To investigate whether risk aversion plays a role for subjects' investment decision-making in our experiment, we regress subjects' investment choice in different projects on the number of safe choices in the Holt and Laury task and report the results in Table IX.

We find that, on average, more risk-averse subjects invest less: the coefficient for the Num. of Safe Choices variable is negative in all individual project models as well as in the model with Average Investment as the dependent variable. Note also that, in line with our expectations, subjects' risk aversion has the biggest effect on their investment in the Risky Project: the coefficient is the largest in absolute value in model (5). Most importantly, the coefficient for overconfidence is unaffected in all models. ${ }^{20}$

20. The correlation coefficient between the measures of risk aversion and overconfidence is only -0.06 , which eliminates any multicollinearity concerns. 


\section{Discussion}

Taken together, our results support predictions 1 and 2: the investment levels chosen by the subjects are positively affected by their overconfidence levels and this relationship holds for underconfidence as well. Subjects with high overconfidence in their financial knowledge tend to overinvest: they choose higher investment levels in comparison with their more diffident peers. This relationship is independent of the monetary reward at stake as the same findings arise in the student sample in the incentivecompatible task and in the professional sample under the hypothetical choice conditions. The previous literature shows that overconfidence may lead to suboptimal choices even in cases with high stakes in a context of investment decisions or corporate decision-making. For example, overestimation of one's abilities leads to excess entry into competitive markets and substantial monetary losses (Camerer and Lovallo (1999)). Moreover, overconfident individuals are more likely to self-select into convex (vs. linear) incentive schemes, generating personal losses even in the presence of clear feedback (Larkin and Leider (2012)). Overconfident individual investors overestimate their ability to select good stocks and to time their trades. As a result, they engage in excessive trading and bear increased trading costs, which considerably reduce their net returns (Barber and Odean (2001); Fenton-O'Creevy et al. (2003); Merkle (2013)).

In the corporate world, it is usually not managers themselves but rather their shareholders, who pay the costs of managerial hubris. Malmendier and Tate (2005) demonstrate that overconfident CEOs make sub-optimal investments: in presence of excess cash, those CEOs overinvest in new projects, and underinvest (and thus forego investments yielding positive net present values) if they need to attract external funding and are hence forced to undergo the scrutiny of bank creditors or financial markets.

Such (symmetrically) suboptimal investment strategies result in a higher cash-flow sensitivity of investments. Moreover, Malmendier et al. (2011) find that overconfident CEOs use less external capital and, in particular, issue less equity than their peers. The fact that overconfident CEOs prefer less control from the providers of outside funding which leads them to hoard cash is also reflected in their payout policy: they retain more cash and pay less dividends (Deshmukh et al. (2013)). Moreover, overconfident CEOs make poor takeover decisions by paying higher takeover premiums than less overconfident CEOs (Malmendier and Tate (2008); Aktas et al. (2016)). The pressure to deliver instigates overconfident CEOs to manage (or manipulate) earnings more often in comparison with their peers (Schrand and Zechman (2012); Hribar and Yang (2015)).

Although all these previous findings suggest that (strong) overconfidence ends in poor decision making, it is important to note that these papers are using only proxies of overconfidence, e.g. press portraits, 
the managers' personal exposure to firm-specific risk captured by individual holdings of their firms' stock options, and the timing of option exercises. Despite their broad acceptance, the justification and consistency of those measures have been rather low so far. For example, in the study by Malmendier and Tate (2008) the correlation between overconfidence proxies by press portraits and by managerial stock-option holdings is never above 0.10. Our study rationalizes the convention for using managers' investment decisions as proxy for their beliefs about their abilities as we confirm a positive relation between overconfidence and investment decisions.

The theoretical literature predicts that in some cases, agents' overconfidence may result in Paretoimprovements or alleviate the negative effects of agents' risk aversion. Gervais and Goldstein (2007) study a model of a firm where the marginal productivity of agents' efforts is amplified by the efforts of their peers. They show that in such a firm all agents can be better off in the presence of an overconfident agent, who overestimates her marginal productivity and applies excessive effort. Gervais, Heaton and Odean (2011) theoretically predict that moderately overconfident CEOs are preferred by boards of directors because it is cheaper for firms to motivate them to pursue valuable risky projects and also because they are committed to exert more effort to learn about the projects. Campbell et al. (2011) theoretically show that overconfidence reduces the underinvestment resulting from CEOs' risk aversion and, subsequently, moderately overconfident and risk-averse CEOs invest at a level closer to the one preferred by risk-neutral shareholders. It is precisely the moderately overconfident subjects in our experiment who choose accurate investment levels, whereas their well-calibrated peers underinvest. In practice, managerial effort is not observable or measurable for researchers but available to boards of directors or employers. If indeed, as predicted by the theory, moderately overconfident managers do not only provide appropriate investment levels but also exert higher effort, then firms' preferences for such managers may be well justified. It is also likely that the optimal levels of overconfidence would be industry- and even firm-specific.

Hirshleifer, Low and Teoh (2012) suggest that the interplay between a CEO's risk aversion and overconfidence plays a crucial role in her pursuit of innovative projects. They show that overconfident CEOs (proxied by stock-option holdings) invest more in R\&D, achieve greater success in innovation, and are better at exploiting growth opportunities in innovative industries. Our results are in line with those of Hirshleifer et al. (2012) in the sense that a CEO's overconfidence, which triggers higher investment, can be beneficial in the context of innovative projects (see also Galasso and Simcoe (2011)). On the one hand, in a context where there is a danger of overinvestment such as empire building, we expect strong overconfidence to be detrimental in terms of shareholder value. On the other hand, given the high risk and uncertainty in growth industries, high levels of CEOs' overconfidence may be necessary to overcome their risk aversion. Our results confirm that managers' overconfidence and risk aversion respectively 
boost and curb investments. Thus, as it would be optimal to attract more overconfident managers in riskier industries, one would expect a positive correlation between industry-specific risk levels and CEO overconfidence.

While the effects of overconfidence on economic behavior have been studied, relatively few papers examine the effects of underconfidence on individual decision-making. Individuals who underestimate their abilities may withdraw from certain activities or decrease their effort although it may be still beneficial for them to persist. In corporate decision-making, underconfidence is also likely to play an important role. Hence, we believe that further research should pay more attention to both under- and overconfidence and their effects on decision-making, rather than consider overconfidence alone.

Our finding that subjects with higher financial literacy are better in choosing optimal investment levels ties in with the literature that studies the relation between financial literature and the quality of economic decisions. More numerate and financially literate individuals are more likely to participate in financial markets (Van Rooij et al. (2011), Almenberg and Dreber (2015)), make fewer mistakes in their investment strategies (Calvet et al. (2009)), engage in retirement planning and as a result accumulate more wealth for retirement (Lusardi and Mitchell (2011)). They are also less likely to use high-cost debt (Lusardi and Tufano (2009)) and to have expensive mortgages (Campbell (2006)). Finally, Aier et al. (2005) show that CFO's financial expertise is negatively correlated with accounting errors and earnings restatements.

To make sure that our results are based on subjects' deliberate choices, we have controlled for the subjects' scores in the Cognitive Reflection Test (CRT) that captures intuitive/rational decision making. The test idea is based on dual-system theory (Kahneman and Frederick (2002); Frederick (2005)), which argues that decision processes are moderated by two types of cognitive processes: System 1 processes are executed quickly without much reflection, whereas System 2 processes are more deliberate, requiring conscious thought and effort. The questions in the CRT have two answers: an immediate (intuitive) incorrect response, attractive for System 1 and a correct response requiring deliberation, i.e. the activation of System 2. Toplak, West and Stanovich (2011) argue that the CRT scores capture a combination of cognitive capacity and disposition for judgement and that they reflect aspects of rational thinking that are not measured in other intelligence tests. When we exclude those subjects that make almost exclusively intuitive choices in the CRT (0 or 1 correct answers) and replicate the analysis for Table VII, we find that the above results are virtually unchanged.

Finally, compared to a standard experimental study involving only student participants we have done one extra step from "confidence-in-the-small" to "confidence-in-the-large." We first run the experiment with students and then continue with professionals who have extensive experience in managing large-scale 
investment projects. Our results are virtually the same in both samples: confidence positively affects investment. While we agree that our results are unlikely to be generalizable to all possible environments, we believe that they provide a valuable insight into individuals' behavior.

For any results, documented both in the lab and in the field, it is natural to ask if they also apply to other settings. Vernon Smith (1982) argues that parallelism is "a sufficient condition for transferability of results", which he defines as follows:

Parallelism: Propositions about the behavior of individuals and the performance of institutions that have been tested in laboratory microeconomies apply also to nonlaboratory microeconomies where similar ceteris paribus conditions hold. (Smith (1982), p.936).

In our case, parallelism does not state that large-scale investment projects are indistinguishable from our small-stake projects, or that company managers in real life behave identically to the student and professional participants to our experiment. What parallelism hypothesizes is that if higher confidence produces higher investments in our experimental setting, it will do so in other settings too. Given that our results are robust for professional and student samples, across lab-, paper-, and web-based experimental designs, and across different incentive schemes, we have no evidence to refute the parallelism hypothesis.

\section{Limitations}

A caveat in relation to the web-based version of our experiment is that we cannot guarantee that professionals do not use external help while answering financial knowledge questions. Yet, we believe that potential cheating was very limited for several reasons. First, the subjects were explicitly asked not to use any external sources to check their answers: once in the invitation (two thirds of the participants were personally rang and asked to give their word not to use any help and one third was reached by e-mail and received the same request) and also in the experimental instructions. The ones who were reached by phone gave their word of honour that they would not look up answers on the web. Second, checking the answers would have made the professionals in the web-based sample more confident in their answers:

they would have known for sure that their answers were correct. However, their confidence levels were not significantly different from those of the professionals in the paper-based sample. Third, professionals could not acquire any monetary or prestige benefits from cheating, which also discourages lying behavior (Gneezy (2005)); indeed, they were guaranteed that their answers would be treated confidentially. Fourth, as the use of external devices is time consuming, cheating would predict a positive relation between time on task and performance but we found no evidence for such a relation.

The next caveat to our design concerns the different incentives used for students and professionals. 
We deliberately asked professionals to make only hypothetical choices mostly for reasons of cheatingprevention (see above) and anonymity. In the web-based sample, asking for subjects' names and bank account numbers to transfer their earnings would strip the professionals of their anonymity. Moreover, while for students opportunity costs were alike and equal to an average hourly wage for unqualified labor force, opportunity costs for professionals are likely to be much more heterogeneous, depending on qualification, current position, age, etc. So even paying "an average professional hourly wage" would not make professionals' incentives equal within the sample. In this, we follow Biais and Weber (2009) who incentivized students but not professionals.

Finally, our design does not allow for learning as no feedback is provided before subjects make their investment decisions. Providing feedback could weaken the relationship between confidence and investment, which is the main objective of study. Still, providing feedback is unlikely to totally eliminate the relation between confidence and investment, especially in real life where feedback is often noisy and negative feedback is often largely ignored (Hilary and Menzly (2006)). Despite those caveats, we believe that our results provide a valuable insight into behavior.

\section{Conclusion}

Self-confidence is considered as a valuable individual trait because it enhances motivation and stimulates a person to reach profitable long-term goals, even when facing short-term negative outcomes. This study considers how individuals' confidence in their own abilities affects their decision to invest. Despite the strong monetary incentives to accurately estimate their skill levels, many subjects in our experiment misjudge their abilities systematically: higher confidence results in higher investment levels. In our experiment, moderate overconfidence is still advantageous and leads to accurate investment levels, both extreme overconfidence and underconfidence result in considerable costs and suboptimal (corporate) decision-making. Subjects who are substantially overconfident with respect to their own skill (in absolute terms or relative to their peers) choose inappropriately high investment levels, whereas underconfident subjects make insufficient investments. Our results are robust for professionals and laymen (students

in economics, finance, and business) with knowledge in the same domain as the decision task (financial economics) and across lab-, paper-, and web-based experimental designs. 


\section{REFERENCES}

Aier, Jagadison K, Joseph Comprix, Matthew T Gunlock and Deanna Lee (2005), 'The financial expertise of CFOs and accounting restatements', Accounting Horizons 19(3), 123-135.

Aktas, Nihat, Eric de Bodt, Helen Bollaert and Richard Roll (2016), 'CEO narcissism and the takeover process: From private initiation to deal completion', Journal of Financial and Quantitative Analysis 51(01), 113-137.

Almenberg, Johan and Anna Dreber (2015), 'Gender, stock market participation and financial literacy', Economics Letters 137, 140-142.

Amir, Ofra and David Rand (2012), 'Economic games on the internet: The effect of $\$ 1$ stakes', PloS One $7(2)$, e 31461.

Anderhub, Vital, Rudolf Müller and Carsten Schmidt (2001), 'Design and evaluation of an economic experiment via the internet', Journal of Economic Behavior $\&$ Organization 46(2), 227-247.

Barber, Brad M and Terrance Odean (2001), 'Boys will be boys: Gender, overconfidence, and common stock investment', The Quarterly Journal of Economics pp. 261-292.

Ben-David, Itzhak, John R Graham and Campbell R Harvey (2013), 'Managerial miscalibration', The Quarterly Journal of Economics 128, 1547-1584.

Biais, Bruno and Martin Weber (2009), 'Hindsight bias, risk perception, and investment performance', Management Science 55(6), 1018-1029.

Calvet, Laurent E, John Y Campbell and Paolo Sodini (2009), 'Measuring the financial sophistication of households', National Bureau of Economic Research .

Camerer, Colin and Dan Lovallo (1999), 'Overconfidence and excess entry: An experimental approach', American Economic Review pp. 306-318.

Campbell, John Y (2006), 'Household finance', The Journal of Finance 61(4), 1553-1604.

Campbell, T Colin, Michael Gallmeyer, Shane A Johnson, Jessica Rutherford and Brooke W Stanley (2011), 'CEO optimism and forced turnover', Journal of Financial Economics 101(3), 695-712.

Chesney, Thomas, Swee-Hoon Chuah and Robert Hoffmann (2009), 'Virtual world experimentation: An exploratory study', Journal of Economic Behavior \&3 Organization 72(1), 618-635. 
Deshmukh, Sanjay, Anand M Goel and Keith M Howe (2013), 'CEO overconfidence and dividend policy', Journal of Financial Intermediation 22(3), 440-463.

Duersch, Peter, Jörg Oechssler and Burkhard C Schipper (2009), 'Incentives for subjects in internet experiments', Economics Letters 105(1), 120-122.

Fenton-O'Creevy, Mark, Nigel Nicholson, Emma Soane and Paul Willman (2003), 'Trading on illusions: Unrealistic perceptions of control and trading performance', Journal of Occupational and Organizational Psychology 76(1), 53-68.

Fischbacher, Urs (2007), 'z-tree: Zurich toolbox for ready-made economic experiments', Experimental Economics 10(2), 171-178.

Fréchette, Guillaume R (2011), 'Laboratory experiments: Professionals versus students'. Working paper, New York University.

Frederick, Shane (2005), 'Cognitive reflection and decision making', Journal of Economic Perspectives pp. $25-42$.

Galasso, Alberto and Timothy S Simcoe (2011), 'CEO overconfidence and innovation', Management Science 57(8), 1469-1484.

Gervais, Simon and Itay Goldstein (2007), 'The positive effects of biased self-perceptions in firms', Review of Finance 11(3), 453-496.

Gervais, Simon, JB Heaton and Terrance Odean (2011), 'Overconfidence, compensation contracts, and capital budgeting', The Journal of Finance 66(5), 1735-1777.

Glaser, Markus, Thomas Langer and Martin Weber (2007), 'On the trend recognition and forecasting ability of professional traders', Decision Analysis 4(4), 176-193.

Glaser, Markus, Thomas Langer and Martin Weber (2013), 'True overconfidence in interval estimates: Evidence based on a new measure of miscalibration', Journal of Behavioral Decision Making 26(5), 405417.

Gneezy, Uri (2005), 'Deception: The role of consequences', American Economic Review pp. 384-394.

Gosling, Samuel D, Simine Vazire, Sanjay Srivastava and Oliver P John (2004), 'Should we trust webbased studies? A comparative analysis of six preconceptions about internet questionnaires.', American Psychologist 59(2), 93. 
Hilary, Gilles and Lior Menzly (2006), 'Does past success lead analysts to become overconfident?', Management Science 52(4), 489-500.

Hirshleifer, David, Angie Low and Siew Hong Teoh (2012), 'Are overconfident ceos better innovators?', The Journal of Finance 67(4), 1457-1498.

Holt, Charles A and Susan K Laury (2002), 'Risk aversion and incentive effects', The American Economic Review 92(5), 1644-1655.

Horton, John J, David G Rand and Richard J Zeckhauser (2011), 'The online laboratory: Conducting experiments in a real labor market', Experimental Economics 14(3), 399-425.

Hribar, Paul and Holly Yang (2015), 'CEO overconfidence and management forecasting', Contemporary Accounting Research .

Kahneman, Daniel and Shane Frederick (2002), 'Representativeness revisited: Attribute substitution in intuitive judgment', Heuristics and biases: The psychology of intuitive judgment 49.

Larkin, Ian and Stephen Leider (2012), 'Incentive schemes, sorting, and behavioral biases of employees: Experimental evidence', American Economic Journal: Microeconomics 4(2), 184-214.

Lusardi, Annamaria and Olivia S Mitchell (2011), 'Financial literacy around the world: an overview', Journal of Pension Economics and Finance 10(04), 497-508.

Lusardi, Annamaria and Olivia S Mitchell (2014), 'The economic importance of financial literacy: Theory and evidence', Journal of Economic Literature 52(1), 5-44.

Lusardi, Annamaria and Peter Tufano (2009), 'Debt literacy, financial experiences, and overindebtedness', National Bureau of Economic Research .

Malmendier, Ulrike and Geoffrey Tate (2005), 'CEO overconfidence and corporate investment', The Journal of Finance 60(6), 2661-2700.

Malmendier, Ulrike and Geoffrey Tate (2008), 'Who makes acquisitions? CEO overconfidence and the market's reaction', Journal of Financial Economics 89(1), 20-43.

Malmendier, Ulrike, Geoffrey Tate and Jon Yan (2011), 'Overconfidence and early-life experiences: the effect of managerial traits on corporate financial policies', The Journal of Finance 66(5), 1687-1733.

Menkhoff, Lukas, Maik Schmeling and Ulrich Schmidt (2013), 'Overconfidence, experience, and professionalism: An experimental study', Journal of Economic Behavior \& Organization 86, 92-101. 
Merkle, Christoph (2013), Financial overconfidence over time-foresight, hindsight, and insight of investors. AFA 2013 San Diego Meetings paper.

Moore, Don A and Paul J Healy (2008), 'The trouble with overconfidence.', Psychological Review $\mathbf{1 1 5}(2), 502$.

Schrand, Catherine M and Sarah LC Zechman (2012), 'Executive overconfidence and the slippery slope to financial misreporting', Journal of Accounting and Economics 53(1), 311-329.

Smith, Vernon L (1982), 'Microeconomic systems as an experimental science', The American Economic Review 72(5), 923-955.

Toplak, Maggie E, Richard F West and Keith E Stanovich (2011), 'The cognitive reflection test as a predictor of performance on heuristics-and-biases tasks', Memory \& Cognition 39(7), 1275-1289.

Van Rooij, Maarten, Annamaria Lusardi and Rob Alessie (2011), 'Financial literacy and stock market participation', Journal of Financial Economics 101(2), 449-472. 


\section{Appendix A Financial Knowledge Questionnaire}

The appendix presents twenty financial knowledge questions with two alternative answers each; the correct answer is in bold.

1. Inflation may create problems in many ways. Which group would have the greatest problem during periods of high inflation that last several years? (i) Older people living on fixed retirement income; (ii) Young working couples with children and a mortgage.

2. If interest rates rise, what will typically happen to bond prices? (i) Fall; (ii) Rise.

3. Buying a single company's stock usually provides (i) a safer return than a stock mutual fund; (ii) a riskier return than a stock mutual fund.

4. Justin just found a job with a take-home pay of $€ 2,000$ per month. He must pay $€ 800$ for rent and $€ 200$ for groceries each month. He also spends $€ 200$ per month on transportation. If he budgets $€ 100$ each month for clothing, $€ 150$ for restaurants and $€ 250$ for everything else, how long will it take him to accumulate savings of $€ 900$. (Assume no interest rate payment on savings). (i) 3 months; (ii) 5 months.

5. A young person with $\$ 100,000$ to invest should hold riskier financial investments than an older person with $\$ 100,000$ to invest. (i) True; (ii) False.

6. An investor wants to buy a house but does not have sufficient funds. She invests in a risky project and her investment (including the returns) doubles in size every quarter. If it takes 48 quarters to reach the necessary funds to purchase the house, how many quarters would it take to have sufficient funds to purchase half of the house? (i) 24 quarters; (ii) 47 quarters.

7. Scott and Eric are young men. Each has a good credit history. They work at the same company and make approximately the same salary. Scott has borrowed $€ 6,000$ to take a foreign vacation. Eric has borrowed $€ 6,000$ to buy a car. Who is likely to pay the lowest finance charge? (i) Eric will pay less because the car is collateral for the loan; (ii) They will both pay the same because consumer credits have the same interest rate.

8. Elena started her pension program at age 20 and put in $€ 2,000$ each year for 15 years. Rebecca started her pension program at age 35 and put in $€ 2,000$ each year for 30 years. If they both get $6 \%$ per year on their investments, who will have more money at age 65? (i) Elena; (ii) Rebecca.

9. Employees should have the majority of their retirement funds in their current employers stock. (i) True; (ii) False.

10. If it takes 5 machines 5 minutes to make 5 widgets, how long would it take 100 machines to make 100 widgets? (i) 5 minutes; (ii) 100 minutes.

11. It is possible for investors to be diversified even if they invest all their money in one mutual fund. (i) True; (ii) False.

12. You should rather have $\$ 5,000$ than a Euro cent doubled every day for a month. (i) True; (ii) False.

13. Yolanda has three credit cards and she owes $€ 500$ on each of them. The interest rates are $7 \%$ for card A, $9 \%$ for card $\mathrm{B}$ and $8 \%$ for card $\mathrm{C}$. If Yolanda has $€ 1,000$ to pay off her debt, which cards should she pay if she wants to 
minimize future interest payments? (i) $€ 500$ to card B and $€ 500$ to card C; (ii) $€ 333$ to card A and $€ 334$ to card B and $€ 333$ to card C.

14. How do income taxes affect the income that people have to spend? (i) They decrease spendable income in deflationary times and increase spendable income in inflationary times. (ii) They decrease the amount of goods and services that can be purchased.

15. A bat and a ball cost 1.10 Euro in total. The bat cost 1 Euro more than the ball. How much does the ball cost? (i) 0.10 Euro; (ii) 0.05 Euro.

16. At takeovers, the bidding firm usually pays a large premium to the target firm. Therefore, upon announcement, the target firm's share price increases substantially as it anticipates the premium to be paid in the takeover. Hence, if you own shares of a target firm (before the announcement), you will very likely make a large profit if you sell them after the announcement. (i) True; (ii) False.

17. You invest $€ 1000$ in a project and the discount factor is $10 \%$. The return is expected to be $€ 1100$ in year 1 and $€ 1200$ in year 2 (when the project ends). The net present value is approximately: (i) $€ 1000$; (ii) $€ 1300$.

18. If you have to sell one of your stocks, you should sell one which has gone up in price rather than one which has gone down. (i) True; (ii) False.

19. To do well in the stock market, you should buy and sell your stocks often. (i)True; (ii) False.

20. The cost of capital of the average listed firm is about (i) $\mathbf{1 0 \%}$; (ii) $20 \%$. 


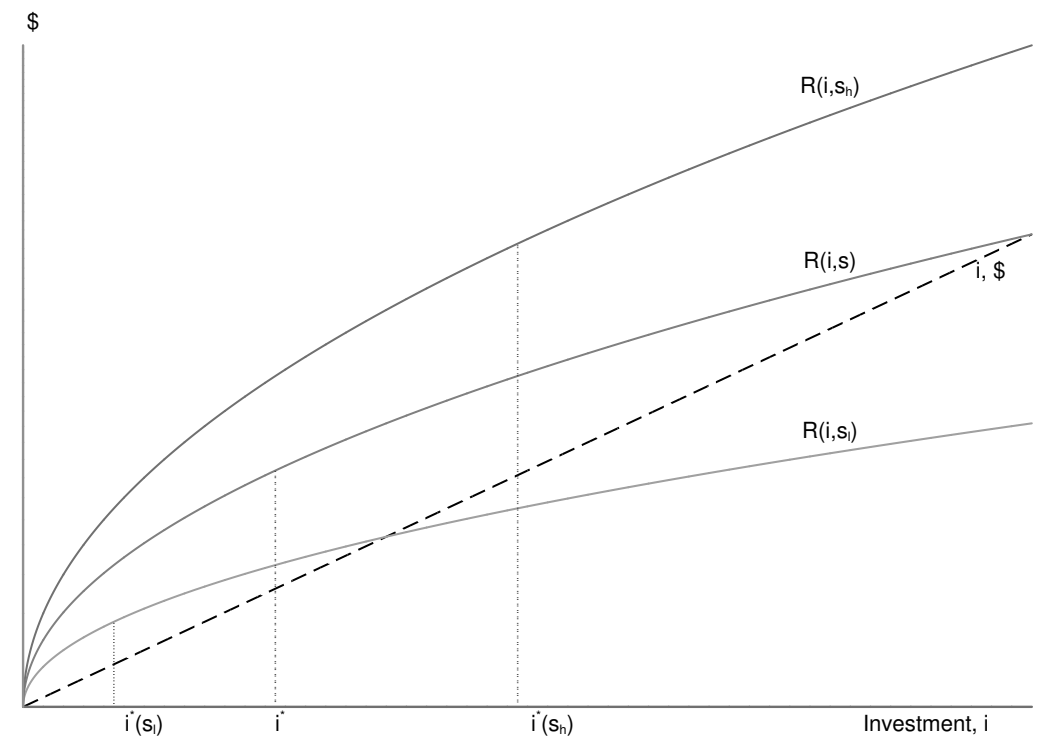

Figure I: Revenue Function and Investment

The figure depicts how project's revenues depend on managerial investment $i$ and skill level $s$, where $s_{l}<s<s_{h}$. An overconfident manager $\tilde{s}_{o c}=s_{h}$ chooses higher than optimal investment levels, $i^{*}\left(s_{h}\right)>i^{*}$ and bears unnecessary costs that decrease her final profit, whereas an underconfident manager $\tilde{s}_{u c}=s_{l}$ chooses sub-optimally low investment levels $i^{*}\left(s_{l}\right)<i^{*}$ and suffers from underproduction.

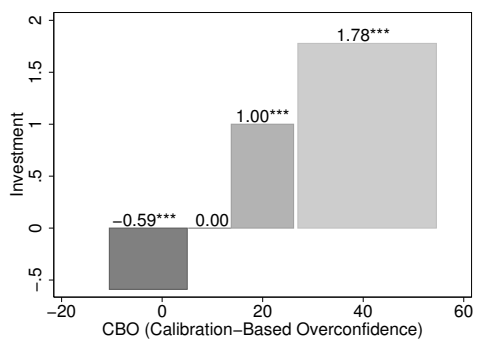

(a) Lab-based student sample

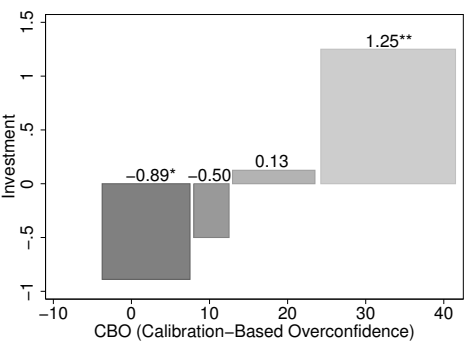

(b) Paper-based professional sample

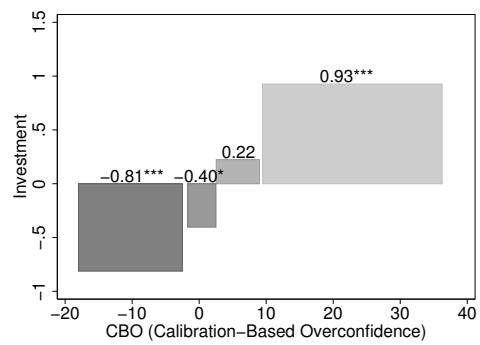

(c) Web-based professional sample

Figure II: Investment ACross CBO QuARTiles

The figure plots the subjects' average investment choice across CBO quartiles, whereby the top quartile consists of the subjects with the highest level of overconfidence. To control for the subjects' skill level, Investment is defined as the difference between the average investment level choice across all available projects and Skill. CBO (Calibration-based overconfidence) is the difference between the average subject's confidence in her answers in the questionnaire and the actual number of correct answers she gave, divided by the total number of questions. For each subject sample and for each CBO quartile, the average investment level is reported as well as whether this level is statistically different from zero. ${ }^{*}$ stands for $p<0.10,{ }^{* *}$ for $p<0.05$, and ${ }^{* * *}$ for $p<0.01$ of two-tailed t-test.

Table I: Number of Correct Answers and Skill Level

\begin{tabular}{l|ccccc}
\hline Number of correct answers & 11 or less & 12 or 13 & 14 or 15 & 16 or 17 & 18 or more \\
Skill level & 1 & 2 & 3 & 4 & 5 \\
\hline
\end{tabular}




\section{TABle II: InVESTMent Projects}

The table presents the revenues and investment cost (both in cents) for actual skill levels and chosen investment levels by investment project. The investment cost (last column) depends only on the chosen investment level and does not depend on the subject's skill level. In each project, the subject's final earnings are equal to revenues plus an endowment of 500 cent minus the investment cost.

\begin{tabular}{|c|c|c|c|c|c|c|}
\hline Investment level & Skill 1 & Skill 2 & Skill 3 & Skill 4 & Skill 5 & Cost of investment \\
\hline \multicolumn{7}{|c|}{ Panel A: Basic Project } \\
\hline 1 & 400 & 490 & 530 & 550 & 565 & 60 \\
\hline $\begin{array}{l}1 \\
2\end{array}$ & 440 & 600 & 690 & 750 & 765 & 130 \\
\hline 3 & 475 & 650 & 850 & 950 & 980 & 220 \\
\hline 4 & 505 & 700 & 900 & 1150 & 1220 & 340 \\
\hline 5 & 530 & 750 & 950 & 1230 & 1500 & 500 \\
\hline
\end{tabular}

Panel B: Strong Incentives Project

\begin{tabular}{c|cccccc}
\hline 1 & 400 & 0 & 0 & 0 & 0 & 0 \\
2 & 0 & 600 & 0 & 0 & 0 & 0 \\
3 & 0 & 0 & 850 & 0 & 0 & 0 \\
4 & 0 & 0 & 0 & 1150 & 0 & 0 \\
5 & 0 & 0 & 0 & 0 & 1500 & 500 \\
\hline
\end{tabular}

Panel C: Loss Aversion Control Project

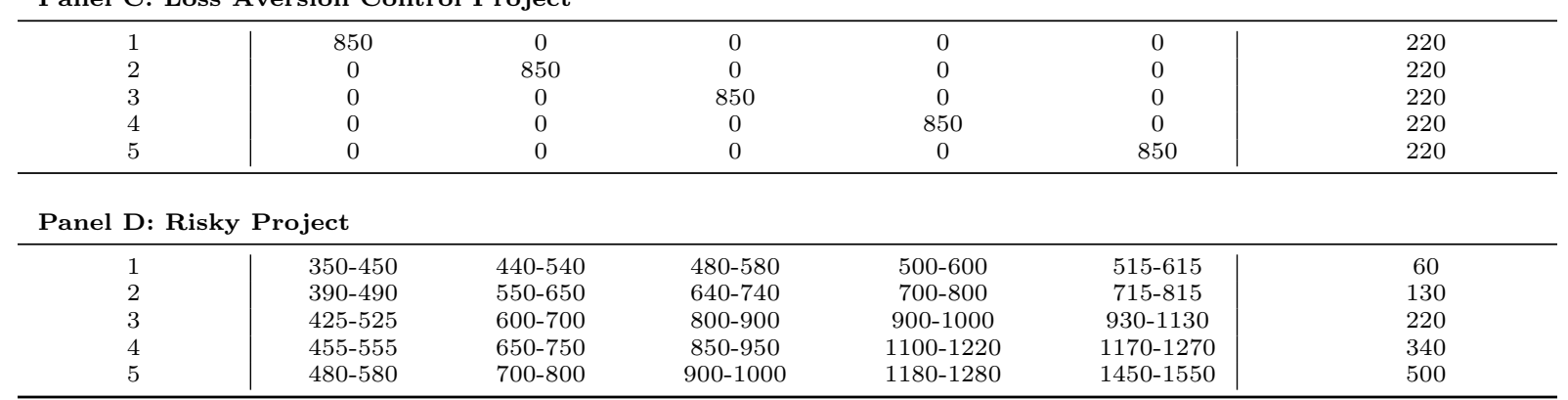




\section{TABle III: Subjects' Characteristics}

The table presents subjects' characteristics for the student lab-based sample (Panel A) and for the professional sample (Panel B). We collect the following information about the subjects during the final questionnaire: Age, gender (Female equals 1 for female subjects and 0 otherwise), Nationality, education (Graduate equa 1 for students studying for a Master degree and 0 otherwise; University degree equals 1 for professionals who have received a university degree (prior to their executive degree - at university) and 0 otherwise (a vocational degree); current Degree for students, where Finance, Econometrics/Operations Research, Accounting, Marketing, and Organization and Strategy majors are classified as 'Business', and Occupation and Working Experience for professionals.

\begin{tabular}{|c|c|c|c|c|}
\hline Panel A: Students & Value & as $\%$ & & \\
\hline Number of subjects & 111 & 100 & & \\
\hline Female & 45 & 40.5 & & \\
\hline Average age (years) & 22.0 & & & \\
\hline Graduate & 55 & 49.6 & & \\
\hline \multicolumn{5}{|l|}{ Nationality } \\
\hline European / Dutch & $60 / 47$ & $54.1 / 42.3$ & & \\
\hline Asian / Chinese & $46 / 44$ & $41.4 / 39.6$ & & \\
\hline Other & 5 & 4.5 & & \\
\hline \multicolumn{5}{|l|}{ Degree } \\
\hline Business & 34 & 30.6 & & \\
\hline Economics & 51 & 46.0 & & \\
\hline Other & 26 & 23.4 & & \\
\hline \multirow[t]{2}{*}{ Panel B: Professionals } & \multicolumn{2}{|c|}{ Paper-based } & \multicolumn{2}{|c|}{ Web-based } \\
\hline & Value & as $\%$ & Value & as $\%$ \\
\hline Number of subjects & 33 & 100 & 114 & 100 \\
\hline Female & 7 & 21.2 & 10 & 8.8 \\
\hline \multicolumn{5}{|l|}{ Age } \\
\hline Below 35 years old & 10 & 30.3 & 23 & 20.2 \\
\hline Between 35 and 45 years old & 12 & 36.4 & 58 & 50.9 \\
\hline Above 45 year old & 11 & 33.3 & 33 & 28.9 \\
\hline \multicolumn{5}{|l|}{ Nationality } \\
\hline European / Dutch & $32 / 30$ & $97.0 / 90.9$ & $113 / 101$ & $99.1 / 88.6$ \\
\hline Asian & 1 & 3 & 0 & 0 \\
\hline Other & 0 & 0 & 1 & 0.9 \\
\hline University degree & 26 & 78.8 & 110 & 96.4 \\
\hline \multicolumn{5}{|l|}{ Working experience } \\
\hline Less than 8 years & 6 & 18.2 & 15 & 13.2 \\
\hline 8-11 years & 7 & 21.2 & 15 & 13.2 \\
\hline $12-16$ years & 7 & 21.2 & 41 & 36.0 \\
\hline More than 16 years & 13 & 39.4 & 43 & 37.6 \\
\hline \multicolumn{5}{|l|}{ Occupation } \\
\hline Banking & 9 & 27.3 & 24 & 11.1 \\
\hline Consulting & 6 & 18.2 & 30 & 26.3 \\
\hline Finance & 6 & 18.2 & 35 & 30.7 \\
\hline Management & 4 & 12.1 & 14 & 12.3 \\
\hline Self-Employed & 6 & 18.2 & 7 & 6.1 \\
\hline Other & 2 & 6.1 & 4 & 3.5 \\
\hline
\end{tabular}




\section{TABle IV: Number of Correct Answers and Overconfidence}

Panel A presents the summary statistics of the number of correct answers given by the subjects, their time spent answering the financial knowledge questions, the calibration-based (CBO), and better-than-average (BtA) overconfidence measures. Panel B presents the results of a t-test, non-parametric median test, and non-parametric Mann-Whitney test (H0: distributions are equal). Panel C reports subjects' performance and (over)confindence across different groups, for the student sample only. We use nonparametric Mann-Whitney tests to compare men and women, Dutch (local) and international subjects as well as those with Business majors and other majors. Confidence is the average subject's confidence in her answers across 20 financial knowledge questions. Time spent is the number of seconds spent by subjects to answer 20 financial knowledge questions in the lab or web-based versions of the experiment. $\mathbf{C B O}$ is the difference between the average subject's confidence in her answers (Confidence) and the actual number of correct answers she gave divided by 20 (the total number of questions). BtA equals 1 for those subjects who believe that they gave more correct answers than their peers, and 0 otherwise. ${ }^{*}$ stands for $p<0.10,{ }^{* *}$ for $p<0.05$, and ${ }^{* * *}$ for $p<0.01$.

\begin{tabular}{|c|c|c|c|c|c|}
\hline & $\begin{array}{c}(1) \\
\text { \# of Cor. Answers }\end{array}$ & $\begin{array}{c}(2) \\
\text { Confidence, } \%\end{array}$ & $\begin{array}{c}(3) \\
\text { Time Spent, sec. }\end{array}$ & $\begin{array}{c}(4) \\
\mathrm{CBO}, \%\end{array}$ & $\begin{array}{c}(5) \\
\text { BtA }\end{array}$ \\
\hline $\begin{array}{l}\text { Panel A: Summary stati } \\
\text { All subjects, } 258 \text { obs. } \\
\text { Mean } \\
\text { Median }\end{array}$ & $\begin{array}{l}15.61 \\
16.00\end{array}$ & $\begin{array}{l}88.00 \\
89.50\end{array}$ & $\begin{array}{r}1017.3 \\
832.6\end{array}$ & $\begin{array}{l}9.94 \\
8.00\end{array}$ & $\begin{array}{l}0.50 \\
1.00\end{array}$ \\
\hline $\begin{array}{l}\text { Students, lab-based, } 111 \\
\text { Mean } \\
\text { Median }\end{array}$ & $\begin{array}{l}14.11 \\
14.00\end{array}$ & $\begin{array}{l}86.03 \\
86.15\end{array}$ & $\begin{array}{l}748.1 \\
738.0\end{array}$ & $\begin{array}{l}15.49 \\
13.65\end{array}$ & $\begin{array}{l}0.56 \\
1.00\end{array}$ \\
\hline $\begin{array}{l}\text { Professionals, paper-base } \\
\text { Mean } \\
\text { Median }\end{array}$ & $\begin{array}{r}\text {, } 33 \text { obs. } \\
15.48 \\
16.00\end{array}$ & $\begin{array}{l}91.09 \\
92.50\end{array}$ & - & $\begin{array}{l}13.67 \\
12.50\end{array}$ & $\begin{array}{l}0.27 \\
0.00\end{array}$ \\
\hline $\begin{array}{l}\text { Professionals, web-based } \\
\text { Mean } \\
\text { Median }\end{array}$ & $\begin{array}{r}114 \text { obs. } \\
17.11 \\
17.00\end{array}$ & $\begin{array}{l}89.03 \\
90.25\end{array}$ & $\begin{array}{l}1279.5 \\
1133.6\end{array}$ & $\begin{array}{l}3.46 \\
2.50\end{array}$ & $\begin{array}{l}0.52 \\
1.00\end{array}$ \\
\hline $\begin{array}{l}\text { Panel B: Tests } \\
\text { Students vs. Professiona } \\
\text { Difference in means } \\
\text { t-statistic } \\
\text { Difference in medians } \\
\text { Chi2-statistic } \\
\text { z-score Mann-Whitney test }\end{array}$ & $\begin{array}{l}\text { web-based } \\
3.00 \\
8.95^{* * *} \\
3.00 \\
37.0^{* * *} \\
7.60^{* * *}\end{array}$ & $\begin{array}{l}3.00 \\
2.77^{* * *} \\
4.10 \\
4.28^{* *} \\
2.83^{* * *}\end{array}$ & $\begin{array}{l}531.4 \\
5.66^{* * *} \\
395.6 \\
15.5^{* * *} \\
5.17^{* * *}\end{array}$ & $\begin{array}{l}-12.03 \\
7.63^{* * *} \\
-11.15 \\
33.6^{* * *} \\
6.70^{* * *}\end{array}$ & $\begin{array}{c}-0.04 \\
0.61 \\
0.00 \\
- \\
0.62\end{array}$ \\
\hline $\begin{array}{l}\text { Professionals, paper-base } \\
\text { Difference in means } \\
\text { t-statistic } \\
\text { Difference in medians } \\
\text { Chi2-statistic } \\
\text { z-score Mann-Whitney test }\end{array}$ & $\begin{array}{l}\text { vs. Professionals } \\
1.63 \\
4.00^{* * *} \\
1.00 \\
8.82^{* * *} \\
3.45^{* * *}\end{array}$ & $\begin{array}{r}\text { b-based } \\
-2.06 \\
1.39 \\
-2.25 \\
0.66 \\
1.67\end{array}$ & $\begin{array}{l}- \\
-\end{array}$ & $\begin{array}{l}-10.20 \\
5.29^{* * *} \\
-10.00 \\
15.7^{* * *} \\
4.63^{* * *}\end{array}$ & $\begin{array}{l}0.25 \\
2.52^{* *} \\
1.00 \\
5.22^{* *} \\
2.48^{* *}\end{array}$ \\
\hline $\begin{array}{l}\text { Panel C: Effect of Stude } \\
\text { Male } \\
\text { Female }\end{array}$ & $\begin{array}{c}\text { ts' Characteristics } \\
14.85^{* * *} \\
13.02\end{array}$ & $\begin{array}{l}\text { obs. } \\
\qquad 87.62^{* * *} \\
83.71\end{array}$ & $\begin{array}{l}742.3 \\
756.5\end{array}$ & $\begin{array}{l}13.37^{*} \\
18.60\end{array}$ & $\begin{array}{l}0.68^{* * *} \\
0.38\end{array}$ \\
\hline $\begin{array}{l}\text { Dutch } \\
\text { International }\end{array}$ & $\begin{array}{l}14.47 \\
13.84\end{array}$ & $\begin{array}{l}86.07 \\
86.01\end{array}$ & $\begin{array}{l}681.3^{* * *} \\
797.1\end{array}$ & $\begin{array}{l}13.73 \\
16.79\end{array}$ & $\begin{array}{l}0.55 \\
0.56\end{array}$ \\
\hline $\begin{array}{l}\text { Business major } \\
\text { Other major }\end{array}$ & $\begin{array}{l}15.29^{* * *} \\
13.58\end{array}$ & $\begin{array}{l}88.34^{*} \\
85.01\end{array}$ & $\begin{array}{l}744.6 \\
749.6\end{array}$ & $\begin{array}{l}11.87^{*} \\
17.09\end{array}$ & $\begin{array}{l}0.71^{* *} \\
0.49\end{array}$ \\
\hline
\end{tabular}

\section{Table V: Skill Level and Subjective Investment Choice}

The table reports subjective investment choices in different Projects (Panel A) and compares those choices with subjects' actual skill level (Panel B). Actual Skill is defined in accordance with Table I. Average Choice is equal to the average investment level choice across all available projects. ${ }^{*}$ stands for $p<0.10,{ }^{* *}$ for $p<0.05$, and ${ }^{* * *}$ for $p<0.01$.

\begin{tabular}{lcr}
\hline & $\begin{array}{c}\text { Student Sample } \\
\text { Lab-based }\end{array}$ & \multicolumn{2}{c}{ Professional Sample } \\
Panel A: Separate Projects & & \\
Paned & 3.45 & 3.00 \\
Basic & 3.30 & 3.00 \\
Strong Incentives & 3.43 & 3.99 \\
Loss Aversion Control & 3.50 & 3.55 \\
Risky & & 3.00 \\
Panel B: Average Choice & 3.42 & 3.03 \\
Average Choice, all Projects & 2.88 & -0.03 \\
Actual Skill & $0.56^{* * *}$ & 3.77 \\
Difference & 4.27 & -0.14 \\
t-statistic & & 0.42 \\
\hline
\end{tabular}




\section{Table VI: Skill and Optimal Investment Level}

The table reports the results for probit regression models of subjects' optimal investment choice. The dependent variable is Optimal Choice, a dummy variable, which equals 1 if a subject chooses an optimal investment level in a given project, i.e., the investment level corresponding to the subject's skill level; 0 otherwise. Skill is defined in accordance with Table I. Each regression includes controls for subjects' gender, age, degree, nationality, and work experience and occupation (the latter two variables are for professionals only). ${ }^{*}$ stands for $p<0.10,{ }^{* *}$ for $p<0.05$, and ${ }^{* * *}$ for $p<0.01$. Robust standard errors are in parentheses.

\begin{tabular}{|c|c|c|c|c|}
\hline & Strong Incentives & Loss Aversion Control & Basic & Risky \\
\hline $\begin{array}{l}\text { Panel A: Studen } \\
\text { Skill }\end{array}$ & $\begin{array}{c}\text { based sample, } 111 \\
0.329^{* * *} \\
(0.108)\end{array}$ & $\begin{array}{c}0.344^{* *} \\
(0.115)\end{array}$ & $\begin{array}{c}0.284^{* *} \\
(0.112)\end{array}$ & $\begin{array}{c}0.275^{* * *} \\
(0.106)\end{array}$ \\
\hline $\begin{array}{l}\text { Subjects' traits } \\
\text { Pseudo R-squared }\end{array}$ & $\begin{array}{l}\text { Yes } \\
0.091\end{array}$ & $\begin{array}{c}\text { Yes } \\
0.095\end{array}$ & $\begin{array}{c}\text { Yes } \\
0.065\end{array}$ & $\begin{array}{l}\text { Yes } \\
0.072\end{array}$ \\
\hline $\begin{array}{l}\text { Panel B: Profess } \\
\text { Skill }\end{array}$ & $\begin{array}{c}\text { paper-based samp } \\
0.035 \\
(0.222)\end{array}$ & $\begin{array}{c}0.035 \\
(0.222)\end{array}$ & & \\
\hline $\begin{array}{l}\text { Subjects' traits } \\
\text { Pseudo R-squared }\end{array}$ & $\begin{array}{c}\text { Yes } \\
0.251\end{array}$ & $\begin{array}{c}\text { Yes } \\
0.251\end{array}$ & & \\
\hline $\begin{array}{l}\text { Panel C: Profess } \\
\text { Skill }\end{array}$ & $\begin{array}{c}\text { web-based sample } \\
0.413^{* * *} \\
(0.144)\end{array}$ & $\begin{array}{c}0.206 \\
(0.134)\end{array}$ & & \\
\hline $\begin{array}{l}\text { Subjects' traits } \\
\text { Pseudo R-squared }\end{array}$ & $\begin{array}{c}\text { Yes } \\
0.104\end{array}$ & $\begin{array}{c}\text { Yes } \\
0.055\end{array}$ & & \\
\hline
\end{tabular}

\section{Table ViI: Impact of Overconfidence on Subjective Investment Choice}

The table reports the results for OLS regression models of subjective investment choice. The dependent variables are Average Investment, equal to the average investment level choice across all available projects, and investment levels in each project. The main explanatory variables are CBO (Calibration-Based Overconfidence) and Skill. CBO is the difference between the average subject's confidence in her answers in the financial knowledge questionnaire and the actual number of correct answers she gave divided by the total number of questions. Skill is defined in accordance with Table I. Each regression includes controls for subjects' gender, age, degree, nationality, and work experience and occupation (the latter two variables are for professionals only). Robust standard errors are in parentheses. ${ }^{*}$ stands for $p<0.10,{ }^{* *}$ for $p<0.05$, and ${ }^{* * *}$ for $p<0.01$.

\begin{tabular}{|c|c|c|c|c|c|}
\hline \multicolumn{6}{|c|}{ Dependent variable } \\
\hline & \multirow[b]{2}{*}{$\begin{array}{c}\text { Average Investment } \\
(1)\end{array}$} & \multicolumn{4}{|c|}{ Investment Choice in Different Individual Projects } \\
\hline & & $\begin{array}{l}\text { Strong Incentives } \\
(2)\end{array}$ & $\begin{array}{c}\text { Loss Aversion Control } \\
\text { (3) }\end{array}$ & $\begin{array}{c}\text { Basic } \\
(4)\end{array}$ & $\begin{array}{l}\text { Risky } \\
(5)\end{array}$ \\
\hline \multicolumn{6}{|c|}{ Panel A: Students, lab-based sample, 111 obs. } \\
\hline $\mathrm{CBO}$ & $\begin{array}{c}0.038^{* * *} \\
(0.010)\end{array}$ & $\begin{array}{c}0.054^{* * *} \\
(0.009)\end{array}$ & $\begin{array}{c}0.035^{* * *} \\
(0.012)\end{array}$ & $\begin{array}{c}0.027^{* *} \\
(0.012)\end{array}$ & $\begin{array}{c}0.036^{* * *} \\
(0.012)\end{array}$ \\
\hline Skill & $\begin{array}{c}0.586^{* * *} \\
(0.109)\end{array}$ & $\begin{array}{c}0.741^{* * *} \\
(0.109)\end{array}$ & $\begin{array}{c}0.549^{* * *} \\
(0.134)\end{array}$ & $\begin{array}{c}0.482^{* * *} \\
(0.137)\end{array}$ & $\begin{array}{c}0.573^{* * *} \\
(0.130)\end{array}$ \\
\hline Subjects' traits & Yes & Yes & Yes & Yes & Yes \\
\hline R-squared & 0.320 & 0.378 & 0.255 & 0.207 & 0.262 \\
\hline \multicolumn{6}{|c|}{ Panel B: Professionals, paper-based sample, 33 obs. } \\
\hline $\mathrm{CBO}$ & $\begin{array}{c}0.078^{* * *} \\
(0.019)\end{array}$ & $\begin{array}{c}0.078^{* * *} \\
(0.019)\end{array}$ & $\begin{array}{c}0.078^{* * *} \\
(0.019)\end{array}$ & & \\
\hline Skill & $\begin{array}{c}0.934^{* * *} \\
(0.182)\end{array}$ & $\begin{array}{c}0.934^{* * *} \\
(0.182)\end{array}$ & $\begin{array}{c}0.934^{* * *} \\
(0.182)\end{array}$ & & \\
\hline Subjects' traits & Yes & Yes & Yes & & \\
\hline R-squared & 0.480 & 0.480 & 0.480 & & \\
\hline \multicolumn{6}{|c|}{ Panel C: Professionals, web-based sample, 114 obs. } \\
\hline $\mathrm{CBO}$ & $\begin{array}{c}0.051^{* * *} \\
(0.011)\end{array}$ & $\begin{array}{r}0.031^{* *} \\
(0.015)\end{array}$ & $\begin{array}{c}0.071^{* * *} \\
(0.016)\end{array}$ & & \\
\hline Skill & $\begin{array}{c}0.625^{* * *} \\
(0.117)\end{array}$ & $\begin{array}{l}0.277^{*} \\
(0.145)\end{array}$ & $\begin{array}{c}0.973^{* * *} \\
(0.158)\end{array}$ & & \\
\hline Subjects' traits & Yes & Yes & Yes & & \\
\hline R-squared & 0.311 & 0.197 & 0.289 & & \\
\hline
\end{tabular}




\section{Table ViII: Calibration-Based Overconfidence vs. Better-than-Average}

The table reports the results of OLS regression models of Investment. The dependent variable is Average Investment. The main explanatory variables are CBO, BtA, and Skill. Average Investment, Skill, and CBO are defined as in Table VII. High CBO is a dummy variable equal to 1 if $\mathrm{CBO}$ is above the median value; 0 otherwise. BtA equals 1 for subjects who believe that they gave more correct answers than their peers, and 0 otherwise. In all models, CBO and Skill are made orthogonal by regressing $\mathrm{CBO}$ on Skill and taking the residual. Each regression includes controls for subjects' gender, age, degree, nationality, and work experience and occupation (the latter two variables are for professionals only). Robust standard errors are in parentheses. ${ }^{*}$ stands for $p<0.10,{ }^{* *}$ for $p<0.05$, and ${ }^{* * *}$ for $p<0.01$.

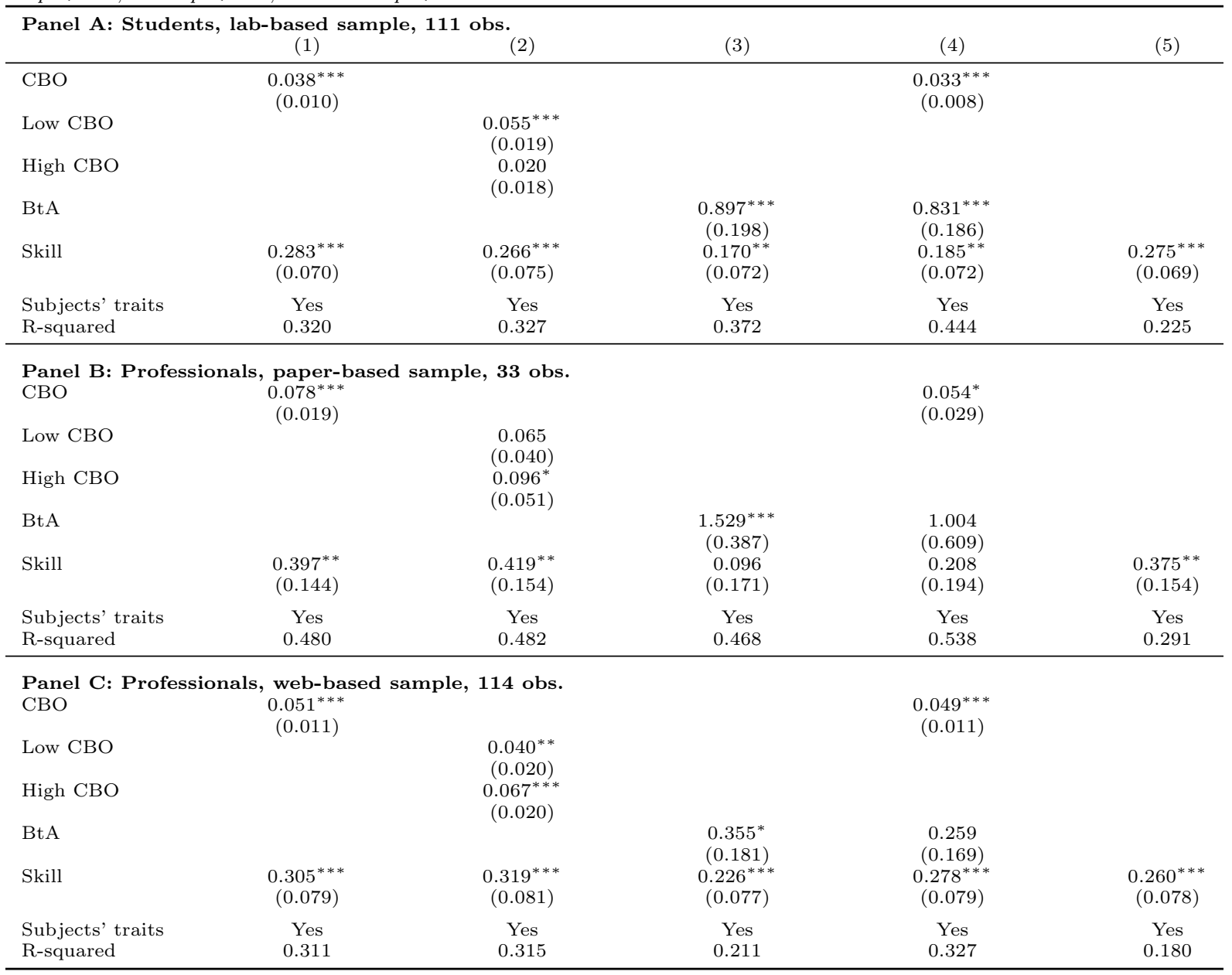

\section{TABle IX: Risk Aversion AND Overcofidence}

The table reports the results for OLS regression models of subjective investment choice. The dependent variables are Average Investment and investment levels in the individual projects. The main explanatory variables are CBO, Skill, and Num. of Safe Choices. Average Investment, Skill, and CBO are defined as in Table VII. Num. of Safe Choices is the number of safe choices a subject makes in the Holt and Laury task and it is between 1 and 10, where higher numbers indicate higher risk aversion. In all models, $\mathrm{CBO}$ and Skill are made orthogonal by regressing $\mathrm{CBO}$ on Skill and taking the residual. Each regression includes controls for subjects' gender, age, degree, and nationality. Robust standard errors are in parentheses. ${ }^{*}$ stands for $p<0.10$, ${ }^{* *}$ for $p<0.05$, and ${ }^{* * *}$ for $p<0.01$.

\begin{tabular}{|c|c|c|c|c|c|}
\hline \multicolumn{6}{|c|}{ Dependent variable } \\
\hline & \multirow[b]{2}{*}{$\begin{array}{l}\text { Average Investment } \\
(1)\end{array}$} & \multicolumn{4}{|c|}{ Investment Choice in Different Individual Projects } \\
\hline & & $\begin{array}{c}\text { Strong Incentives } \\
(2)\end{array}$ & $\begin{array}{c}\text { Loss Aversion Control } \\
(3)\end{array}$ & $\begin{array}{l}\text { Basic } \\
(4)\end{array}$ & $\begin{array}{l}\text { Risky } \\
(5)\end{array}$ \\
\hline $\mathrm{CBO}$ & $\begin{array}{c}0.035^{* * *} \\
(0.011)\end{array}$ & $\begin{array}{c}0.051^{* * *} \\
(0.010)\end{array}$ & $\begin{array}{c}0.030^{* *} \\
(0.013)\end{array}$ & $\begin{array}{c}0.025^{* *} \\
(0.012)\end{array}$ & $\begin{array}{c}0.035^{* *} \\
(0.013)\end{array}$ \\
\hline Num. of Safe Choices & $\begin{array}{c}-0.097^{* *} \\
(0.047)\end{array}$ & $\begin{array}{l}-0.050 \\
(0.048)\end{array}$ & $\begin{array}{c}-0.114^{* *} \\
(0.056)\end{array}$ & $\begin{array}{l}-0.085 \\
(0.060)\end{array}$ & $\begin{array}{c}-0.140^{* *} \\
(0.056)\end{array}$ \\
\hline Skill & $\begin{array}{c}0.310^{* * *} \\
(0.076)\end{array}$ & $\begin{array}{c}0.341^{* * *} \\
(0.078)\end{array}$ & $\begin{array}{c}0.278^{* * *} \\
(0.087)\end{array}$ & $\begin{array}{c}0.295^{* * *} \\
(0.090)\end{array}$ & $\begin{array}{c}0.328^{* * *} \\
(0.090)\end{array}$ \\
\hline Subjects' traits & Yes & Yes & Yes & Yes & Yes \\
\hline R-squared & 0.330 & 0.375 & 0.242 & 0.231 & 0.308 \\
\hline
\end{tabular}

